\title{
Reforma universitária e a construção do Espaço Europeu de Educação Superior: análise de uma década do Processo de Bolonha
}

Roberta Cajaseiras de Carvalho*

Nesta resenha apresenta-se um olhar preliminar sobre a obra Reforma universitária e a construção do Espaço Europeu de Educação Superior: análise de uma década do Processo de Bolonha, organizada por Elisabete Monteiro de Aguiar Pereira e Maria de Lourdes Pinto de Almeida e publicada em 2011 pela editora Mercado de Letras, de Campinas. A obra constitui-se de uma coletânea de artigos científicos que apresentam resultados finais ou parciais de investigações sobre a criação do EEES (Espaço Europeu de Educação Superior) e de sua estruturação política por meio do que se denominou Processo de Bolonha. Os textos apresentados são de autores brasileiros e estrangeiros, o que permite ao leitor acessar avaliações aprofundadas do processo sob o olhar europeu, mas também de iniciar reflexões sobre seus possíveis impactos em países latinos, a exemplo do Brasil.

O primeiro capítulo intitulado O Processo de Bolonha e a formação do Espaço Europeu de Educação Superior - EEES: 10 anos de reforma universitária europeia, explica e contextualiza o Processo de Bolonha, apresentando um breve resgate histórico de sua criação e desenvolvimento até o ano de 2010. Para tanto, a autora Elisabete Monteiro de Aguiar Pereira analisou os documentos produzidos pelas reuniões bianuais entre os países membros. Entre as contribuições importantes do texto está a apresentação dos resultados de uma década de EEES, como: diferentes graus de implementação dos objetivos propostos, por conta de muitas diferenças entre os contextos nacionais e as instituições envolvidas; pouco debate sobre o processo em alguns países; atendimento parcial da dimensão social prevista. Para a autora, a ideia de criação do EEES foi alcançada, mas não completada, e sua efetivação requererá que as ações continuem sendo implementadas por mais dez anos.

O segundo capítulo (O Processo de Bolonha e seu papel nos países em transição, de autoria do professor europeu Pavel Zgaga) apresenta um olhar otimista sobre o processo, destacando o sucesso gerado, principalmente, pela inclusão de mui-

Recebido: 23/04/2015 - Aprovado: 07/08/2015

http://dx.doi.org/10.5335/rep.v22i2.5571

Doutoranda do PPGEDU da UPF, orientanda do prof. Dr. Altair Alberto Fávero. E-mail: robertacajaseiras@gmail.com 
tos países membros ao longo dos anos. Após o ano de 2005, o desafio do Processo de Bolonha passou a ser fazer com que os 47 países integrantes pudessem cooperar no desenvolvimento de políticas, sem perder o poder nas tomadas de decisões. Ainda, segundo o autor, a coesão entre países tão distintos foi essencial para o sucesso do EEES, e foi facilitada pela proposição de quatro linhas de ações combinadas: sistema de crédito europeu generalizado, moldura flexível das qualificações, dimensão europeia de qualidade e inovação e capacitação do povo europeu para as novas oportunidades de aprendizagem. O texto destaca o envolvimento dos países em transição (na ocasião considerados os antigos países socialistas da Europa Central e Oriental) no processo. Entre outros aspectos, Zgaga destaca que, nessas nações, a adesão ao EEES é um caminho para que aperfeiçoem seus sistemas de ensino e motivem a população para a educação superior. Por outro lado, a mobilidade internacional obtém sucesso moderado. Segundo sua análise, o Processo de Bolonha reforça a autonomia universitária e as reformas na educação superior desses países em transição.

O capítulo Dez anos de reformas do ensino superior na Europa, de Andrée Sursock, destaca a ampla consulta durante as tomadas de decisões como um fator de sucesso do Processo de Bolonha. O papel da Associação Europeia de Universidades (EUA) também é lembrado, assim como os relatórios de tendências produzidos pelo grupo, resultado de um intenso acompanhamento do processo ao longo do tempo. Sursock analisa um desses relatórios (Tendências 2010), apresentando um resumo de suas principais conclusões. Entre elas, pode-se destacar: maior acesso ao ensino superior, devido ao aumento do número de instituições; exigência de mudanças de atitudes e valores pelos países; necessidade de se explicar o propósito das reformas e convencer os professores a aderirem ao processo. Segundo os resultados, a adesão dos países ao longo da década culminou em diferentes ritmos de execução, e por isso o processo não foi plenamente implementado. Apesar dos avanços, o autor destaca que o desenvolvimento pessoal não é suficientemente abordado, que ainda não é possível avaliar os impactos da abordagem centrada no aluno, e que a adaptação das instituições ao EEES é desafiadora.

Como condições para o sucesso, Sursock aponta a necessidade de uma maior interação entre governos e instituições de ensino superior, da promoção efetiva da mobilidade, de mais atenção aos serviços estudantis e a qualidade interna das instituições. $\mathrm{O}$ autor conclui o texto apontando uma série de desafios futuros a serem considerados para que o Processo de Bolonha possa vir a ser plenamente implementado.

O quarto texto é de autoria do professor português Antonio Francisco Cachapuz, intitulado Bolonha 2010. Inicialmente, o autor apresenta sua previsão de que 
a meta de integrar o ensino superior europeu não será atingida até 2010, pois alguns dos países que aderiram sequer implantaram o processo. Seu posicionamento crítico parte da visão de que o EEES prevê o planejamento de universidades para atender ao mercado, refletindo uma forte influência das políticas neoliberais. Além disso, apesar do discurso em prol da autonomia, a influência dos governos sobre as universidades aumentou e apenas uma elite de instituições de ensino é beneficiada. Segundo Cachapuz, há uma tendência crítica da Europa ao Processo de Bolonha, e que a questão da empregabilidade dos egressos do primeiro ciclo (bacharéis) ainda gera desconfiança. Entre as alternativas possíveis para minimizar o descompasso do processo, o autor propõe que a comunidade educativa seja mais proativa em relação ao Espaço Europeu de Educação Superior.

O enfoque por competências na educação geral e no ensino superior europeu é o tema do quinto capítulo, de autoria de Antonio Bolívar. O autor destaca que as reformas curriculares atuais se baseiam no Marco de Referência Europeu de Competências Chave (2006) e suas oito competências entre as quais: comunicações em várias línguas, comunicação digital, aprender a aprender, competência cívica e espírito empreendedor. Segundo sua análise, o enfoque das competências básicas na escolaridade obrigatória, se bem conduzido, pode formar parte das oportunidades sociais, estimular um trabalho mais interdisciplinar e promover integração e participação mais ativas dos indivíduos na vida pública. Em contrapartida, o enfoque das competências vinculado ao EEES teve como modelo o Projeto Tuning, que utiliza as competências para delimitar perfis profissionais e substitui a aquisição de conhecimentos, subordinando-se ao mercado de trabalho e ao discurso do "saber vivo". Em contrapartida a esse modelo, Bolívar defende o Proyecto De Se Co, que ele considera como um conceito holístico de competência, mais integrador e completo, aliando requisitos cognitivos e não cognitivos com o contexto vivido. Por fim, afirma que o discurso das competências não é um vilão, dependendo do uso que se faça e de suas finalidades.

O sexto texto é de autoria de Maria Carmem López López, intitulado El processo de Bolonia: professorado y modelo educativo centrado e la aprendizaje de competencias. Para a autora, a pouca atenção dada às mudanças qualitativas e seus impactos sobre os professores e suas práticas são um obstáculo para a consolidação das mudanças previstas pelo Processo de Bolonha. O texto defende uma análise cautelosa do discurso das competências, destacando suas possibilidades e limitações. Destaca o papel essencial dos professores para otimizar o potencial formativo da aprendizagem por competências, e que os documentos norteadores do EEES fazem poucas alusões à importância do docente e de sua formação. A partir de reflexões contextualizadas, a autora lista algumas condições para a participação 
adequada dos professores na consolidação do processo, como a revalorização da docência, a consideração de novas premissas para conduzir a prática docente, $o$ desenvolvimento de uma nova cultura de colaboração, entre outros aspectos. Por fim, apresenta um estudo de caso sobre a Universidade de Granada, ilustrando e reforçando algum de seus comentários.

Ricardo Rossato é o autor do sétimo capítulo, A universidade brasileira face ao processo de Bolonha. Para contextualizar o tema, o autor destaca o perfil dependente do Brasil em relação a outros países e o reflexo disso na criação dos perfis das nossas universidades (tão variadas que não conseguem configurar um sistema). Apresenta a atual conjuntura, destacando a internacionalização da educação (como configuração de um neocolonialismo), a criação de leis que expõem o ensino superior ao capital privado e a vulgarização do próprio conceito de universidade. A título de ilustração, apresenta um quadro comparativo entre os modelos tradicional e emergente de universidade. Utiliza os exemplos da UFBA e da UFABC para demonstrar a influência dos fatores externos no planejamento e gestão de algumas instituições nacionais. Ao se deter no tema políticas públicas, Rossato lembra que ainda não existe no país uma legislação consolidada nem uma política de educação sobre o ensino superior, além de destacar a influência do Processo de Bolonha sobre programas como o Prouni e o Reuni (contemplando a flexibilização curricular e a mobilidade estudantil, por exemplo). Ao final, apresenta um resumo do documento Manifesto dos Reitores das Universidades Brasileiras, publicado em 2006 e sua intenção de reformar a educação superior brasileira em prol de uma adequação aos modelos internacionais, porém sem submissão aos outros países.

O último capítulo do livro traz o texto $\mathrm{O}$ processo de Bolonha na produção acadêmica brasileira: incursões preliminares, de Afrânio Mendes Catani e Renato de Sousa Porto Gilioli. O artigo propôs-se a mapear as produções acadêmicas nacionais que versam sobre o Processo de Bolonha, apresentando o contraste presente entre os debates e um panorama para auxiliar novos estudos. Para os autores, a abordagem do tema na América Latina e no Brasil tendem a seguir as orientações do EEES, e citam como exemplo a implantação polêmica do ensino a distância, a lógica gerencialista dos professores tutores e a presença marcante das ideias neoliberais e suas reformas. Destacam que o Projeto de Lei no 7200/2006 (Lei da Reforma da Educação Superior) fortalece essas constatações, pois prevê a mescla dos modelos europeu e estadunidense em uma nova configuração da educação superior brasileira, e também ilustram, citando os exemplos da UFBA, UnB, UFPI e UFABC, como o modelo norte-americano está sendo implementado no Brasil.

Segundo a análise das publicações selecionadas, Catani e Gilioli identificaram que alguns autores percebem que o Processo de Bolonha tende a aproximar as uni- 
versidades aos preceitos do livre mercado, mas que outras investigações defendem que a necessidade de uma modernização e adaptação aos requisitos da sociedade do conhecimento precisam ser mais consideradas pelo ensino superior brasileiro. Concluem o texto afirmando que o EEES reflete o interesse europeu em aumentar sua hegemonia perante diversos países, entre os quais os latino-americanos.

A obra em questão constitui uma boa fonte de consulta preliminar aos estudos sobre o Processo de Bolonha, permitindo ao público brasileiro e de toda a América Latina (por conter textos em espanhol) compreender como se iniciou e se desenvolve a construção do Espaço Europeu de Educação Superior. A opção pela seleção de textos com perfis distintos (tanto contestando quanto valorizando o atual modelo europeu de formação universitária) contribui para uma análise mais imparcial do leitor, levando à reflexão e ao interesse em aprofundar as leituras sobre as fontes primárias citadas frequentemente em todos os textos. O livro ajuda os pesquisadores em políticas públicas e o público em geral a compreender as influências que regem a configuração do ensino universitário no mundo ocidental contemporâneo, e a necessidade de analisar mais criticamente essas diretrizes que podem por em risco ou potencializar os objetivos almejados por diversos países (europeus ou não) na formação de cidadãos ativos para as futuras gerações.

\section{Referência}

PEREIRA, E. M. A.; ALMEIDA, M. L. P (Org.). Reforma universitária e a construção do Espaço Europeu de Educação Superior: análise de uma década do Processo de Bolonha. Campinas: Mercado de Letras, 2011. 